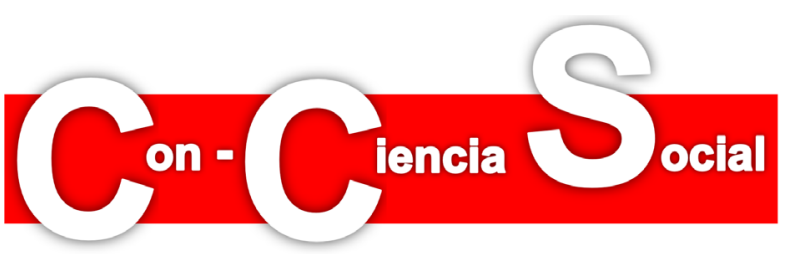

\title{
Enseñanzas de "El Testigo": Pensar la enseñanza de la historia desde las fotografías de Jesús Abad Colorado
}

\author{
Lessons from "El Testigo": Thinking about teaching history from \\ Jesus Abad Colorado's photographs
}

\author{
Sandra Patricia Rodríguez Ávila \\ Universidad Pedagógica Nacional de Colombia \\ srodriguez@pedagogica.edu.co
}

Recibido en enero 2020

Aceptado en enero 2020

DOI:10.7203/con-cienciasocial.3.16798

\section{RESUMEN}

En este artículo se realiza un acercamiento al trabajo del reportero gráfico Jesús Abad Colorado, en particular a las posibilidades que se abren para la enseñanza del pasado reciente con su exposición El Testigo. Memorias del conflicto armado colombiano en el lente y la voz de Jesús Abad Colorado. Inicialmente se presenta una caracterización de la exposición con un análisis de su recepción en distintos medios periodísticos $\mathrm{y}$ en el mismo balance de la experiencia adquirida a través de las visitas realizadas en el marco de actividades pedagógicas o como espectadora de la muestra fotográfica. Posteriormente, se presenta la manera como sus efectos en la opinión pública contribuyen a formular propuestas para la enseñanza del pasado reciente, en particular en el contexto actual en el cual ha empezado a funcionar una Comisión Asesora para la enseñanza de la historia de Colombia definida por el Decreto 1660 de 2019, en cumplimiento de Ley 1874 de 2017 que se propuso restablecer la enseñanza obligatoria de la Historia de Colombia como una disciplina integrada en los lineamientos curriculares de las ciencias sociales en la educación básica y media de 2017 que se propuso restablecer la enseñanza obligatoria de la Historia de Colombia como una disciplina integrada en los lineamientos curriculares de las ciencias sociales en la educación básica y media.

Palabras clave: Fotografía de guerra, conflicto armado colombiano, enseñanza de la historia reciente.

\begin{abstract}
This article is made as an approach to the work of the graphic reporter Jesús Abad Colorado, and to the possibilities that are now being given for the teaching of the "recent past" with his exhibition: El Testigo. Memorias del conflicto armado colombiano en el lente y la voz de Jesús Abad Colorado. Initially, a characterization of the exhibition is presented with an analysis of its reception in different journalistic media and balanced with the experience acquired through visits made within pedagogical activities or as a spectator of the photographic exhibition. Subsequently, the manner in which its effects on public opinion contribute to formulating proposals for the teaching of the recent past, is presented, particularly in the current context in which an advisory commission for the teaching of Colombian history defined by the decree 1660 of 2019, in compliance with Law 1874 of 2017, proposed to restore the compulsory education of the history of Colombia as a full on integrated discipline in the curricular guidelines of the social sciences in basic and secondary education.
\end{abstract}

Keywords: War photography, Colombian armed conflict, teaching current history.

\section{Referencia}

Rodríguez, S. P. (2020). Enseñanzas de "El Testigo": pensar la enseñanza de la historia desde las fotografías de Jesús Abad Colorado. Con-Ciencia Social (segunda época), 3, 197212. DOI:10.7203/con-cienciasocial.3.16798 


\section{INTRODUCCIÓN}

La fotografía se convirtió en una fuente excepcional para testimoniar los hechos ocurridos en el siglo XX. Aunque desde los años cuarenta, el reportaje fotográfico ya aportaba fuentes profundamente controversiales, fundamentalmente acerca de la guerra, que además de documentar lo ocurrido, exigían un lugar ético para interpelar el sentido mismo de estos actos para la humanidad (Sontag, 2019), solo desde los años ochenta se empezaron a producir herramientas teóricas y metodológicas para integrar analíticamente la fotografía, al conjunto de explicaciones que la historia puede producir a propósito de los eventos del pasado reciente (Lara, 2005).

Las primeras fotografías acerca de la guerra eran composiciones de la vida militar o encuadres preparados por los mismos fotógrafos porque primaba la idea de "arreglar los elementos de la foto" (Sontag, 2019, p. 51) como ocurrió con emblemáticas imágenes de victoria en la Segunda Guerra Mundial, cuando los vencedores ondeaban su bandera sobre el campo enemigo, ${ }^{1}$ solo hasta la guerra de Vietnam la fotografía hecha por Huynh Cong Ut testimonió el sufrimiento de las víctimas e interpeló el papel de los periodistas en estos eventos. Desde ese momento las imágenes de guerra según Sontag (2019), de un lado, le otorgan materialidad en la opinión pública a las confrontaciones bélicas y de otro lado, saturan la representación de estos eventos, hasta naturalizar su existencia y sus efectos.

Este tema, ha sido ampliamente analizado en Colombia por quienes desde los estudios visuales buscan comprender la manera como la imagen ha contribuido a representar la realidad del conflicto armado $^{2}$, sin embargo, el debate con estas investigaciones rebasa los límites del presente artículo, por tal razón, esta reflexión se limita, a explorar las potencialidades pedagógicas del trabajo de Jesús Abad Colorado a propósito de la exposición El Testigo. Memorias del conflicto armado colombiano en el lente y la voz de Jesús Abad Colorado, a través de una descripción general de esta muestra fotográfica y de la ubicación de algunas claves para la

\footnotetext{
1 Un ejemplo de la composición fotográfica de la guerra, se observa en Iwa Jima el 23 de febrero de 1945, cuando soldados estadounidenses alzan la bandera de su país y la fotografía que testimonia el hecho resultó ser "una reconstrucción de un fotógrafo de la Associated Press, Joe Rosenthal, de la ceremonia matutina del levantamiento de la bandera que siguió a la captura del Monte Suribachi, reconstruida aquel mismo día pero más tarde y con una bandera más grande y en Berlín el 2 de mayo de 1945" (Sontag, 2019, p. 52).

2 Para un análisis de la fotografía en el marco de investigaciones sobre el conflicto armado, los medios y los estudios visuales ver entre otros autores a Bonilla Vélez (2018), Bonilla Vélez (2015), Simon (2014) y Yepes (2014).
} 
Sandra P. Rodríguez, Enseñanzas de "El Testigo": pensar la...

enseñanza de la historia reciente mediante la utilización de la fotografía como fuente primordial.

\section{EL TESTIGO: UNA EXPOSICIÓN PARA CONTROVERTIR LA VERSIÓN DE LOS VENCEDORES}

Jesús Abad Colorado López es un periodista colombiano que nació en Medellín (Antioquia) en 1967. Estudió comunicación social en la Universidad de Antioquia y es reconocido por su trabajo como reportero gráfico en el diario El Colombiano (1992-2001) y como investigador del Grupo de Memoria Histórica de la Comisión Nacional de Reparación y Reconciliación. ${ }^{3}$

Su trabajo ha sido publicado 4 y premiado en varias ocasiones. ${ }^{5}$ En las distintas reseñas sobre su trayectoria como fotógrafo se destacan varias experiencias que convirtieron el conflicto armado en el centro de su interés periodístico entre las que se destacan dos: la primera, se refiere a su historia familiar, en la cual se registran hechos de violencia desde los años sesenta ligados con la confrontación bipartidista, con la usurpación de tierras y con la actuación de los distintos actores armados que protagonizan la guerra en Colombia desde los años ochenta. Jesús Abad Colorado destaca que sus abuelos y padres se negaron a dejarle el odio como legado, lo cual se aprecia en la misma exposición de El Testigo, donde aparece la fotografía de sus abuelos, como testimonio de su memoria familiar.

La segunda experiencia, corresponde a lo que enfrentó en 1987 cuando cursaba segundo semestre en la Universidad de Antioquia. Ante el asesinato selectivo de 21 profesores y estudiantes defensores de derechos humanos se dio cuenta que la fotografía podría contribuir a restituir lo que la palabra amenazada no podía decir. De ese modo, fue surgiendo una manera novedosa de ser periodista, que no se concentra en la vertiginosa convulsión de la guerra, sino que es capaz de

\footnotetext{
${ }^{3}$ El Grupo de Memoria Histórica (GMH) de la Comisión Nacional de Reparación y Reconciliación (CNRR) se creó por mandato de la Ley de Justicia y Paz (Ley 975 de 2005) y se mantuvo hasta 31 de diciembre de 2011. Sus aportes se incorporaron al Centro Nacional de Memoria Histórica (CNMH), creado mediante la Ley de Víctimas y Restitución de Tierras (Ley 1448 de 2011) y actualmente se encuentra adscrito al Departamento para la Prosperidad Social (DPS).

${ }^{4}$ Sus fotografías aparecieron en Giraldo, Colorado y Pérez (1997). Asimismo, testimonios de la vida en cárceles colombianas fueron captados por el lente de Jesús Abad Colorado en Oficina en Colombia del Alto Comisionado de las Naciones Unidas para los Derechos Humanos (2006). Finalmente, fotografías del conflicto armado colombiano captadas por Colorado por más de dos décadas y análisis de su trabajo periodístico se encuentran en Ponce de León (2015).

5 En Colombia ganó el Premio Nacional de Periodismo Simón Bolívar en tres ocasiones y el Premio Nacional de Fotografía otorgado por el Ministerio de Cultura de Colombia 2018. En el ámbito internacional ha sido reconocido con el premio Caritas (Suiza) por sus contribuciones en la búsqueda de la verdad y la justicia social y con el CPJ International Press Freedom Awards (Estados Unidos) del Comité para la Protección de Periodistas y fue candidato al Prix Pictet. Recientemente fue merecedor del Reconocimiento a la Excelencia del Premio Gabo 2019.
} 
Sandra P. Rodríguez, Enseñanzas de "El Testigo": pensar la...

quedarse pacientemente en las zonas de confrontación para ser testigo de los estragos de estas acciones armadas y de la manera como en medio de esa devastación sobrevive o renace la esperanza. En sus palabras:

[...] la clave está en volver, en contar otras historias, porque yo muchas veces he visto el dolor, pero al frente están niños y niñas que, en esos mismos espacios, a veces sonríen con un fotógrafo, sonríen con un periodista y yo vuelvo a esos mismos lugares, no una sino muchas veces más, para encontrarme a los que sobrevivieron, a los que resisten, a los que le siguen apostando a la vida (Jesús Abad Colorado, Ganador..., 2019).

Desde este enfoque, por más de veinte años recaudó un amplio material visual que recientemente y bajo la coordinación de la comisaria María Belén Sáez de Ibarra, se convirtió en la exposición titulada El Testigo. Memorias del conflicto armado colombiano en el lente y la voz de Jesús Abad Colorado. En octubre de 2018 se inauguró esta muestra fotográfica en el Claustro de San Agustín en Bogotá (Colombia), ${ }^{6}$ que se compone de más de 558 fotografías tomadas entre 1992 y 2018 en varias regiones del país donde ocurrieron hechos relacionados con el conflicto armado colombiano.

La exposición hace parte de un proyecto más amplio con el cual Colorado busca preservar los testimonios compilados durante su trabajo periodístico e investigativo y socializar su experiencia mediante distintas estrategias como la muestra fotográfica que se aborda en este artículo, o la realización del documental El Testigo, Cain y Abel dirigido por Kate Horne, ${ }^{7}$ que en 76 minutos muestra los recorridos hechos por Jesús Abad Colorado buscando a quienes fueron protagonistas de sus fotografías, para contar esas historias que dieron origen a sus testimonios gráficos. Según Ricardo Rondón:

En este documental, la historia gráfica y la narración oral del fotoperiodista, van de la mano. La una entrelaza a la otra, y van conduciendo al espectador como

\footnotetext{
${ }^{6}$ El Claustro de San Agustín es una Casa colonial de mediados del siglo XVIII, considerada patrimonio nacional que desde 2006 hace parte de la Dirección de Patrimonio Cultural de la Universidad Nacional de Colombia. Se ubica en el centro histórico de la capital, donde se localiza un amplio conjunto de museos y algunos de los más importantes organismos de gobierno del Estado colombiano.

${ }^{7}$ Este documental fue proyectado en salas de cine en Bogotá entre el 25 y 28 de octubre de 2018 (Documental "El Testigo"..., 2018) y actualmente hace parte de los documentales de la plataforma Netflix.
} 
en una suerte de vasos comunicantes para ilustrar el paso a paso, con lujo de detalles, nombres, fechas, espacios y acontecimientos que, de tanto nombrarlos en conferencias, charlas universitarias, aulas de escuelas y colegios, y en su retorno a los territorios heridos, se sabe de memoria (Rondón, 2018).

Este documental se articula a la exposición que, en cada fotografía, permite aproximarse a las dimensiones de la guerra a partir de sus efectos sobre la población civil, los combatientes, los excombatientes y las víctimas, que en el lente de este fotógrafo aparecen en escenas cotidianas, que expresan los proyectos vitales arrasados después de cada acción armada, o reconstruidos a propósito de cada intento de paz.

La mayoría de estas fotografías se exhiben en blanco y negro, porque "el color agrede en situaciones de violencia. El blanco y negro le da más carácter de documento, de duelo" (Pérez, 2019). Se acompañan de una narración en primera persona del mismo fotógrafo, quien relata las circunstancias en las que tomó la fotografía, lo que ocurrió con las personas que aparecen en ellas, lo que sintió o lo motivó a tomar la fotografía, y en algunas ocasiones, reproduce la breve conversación que tuvo con ellos.

En los primeros meses de exhibición, los visitantes eran recibidos con una imagen en formato de anuncio o pancarta gigante que cubría la pared del frente de la primera escalera. La imagen es de un dibujo realizado por niños de primaria en el que se aprecia una población ribereña, con varias casas entre las que sobresalen dos iglesias y varios miembros de la comunidad en actividades cotidianas, en el trabajo agrícola, con atarrayas pescando en el río y en labores domésticas. En la parte superior del dibujo aparece la siguiente frase: "Este mural recoge el sentir y la palabra de los niños y las niñas, que cuestionan la guerra, el dolor y el abandono. Nos recuerdan la responsabilidad que implica el NO OLVIDAR. "Soy lo que otros no pudieron ser y por eso no los olvidamos". Grados $4^{\circ}$ y $5^{\circ}$ E.U.M.B. ${ }^{8}$

Después los visitantes llegan a las salas en las que se exhiben las fotografías, sin un orden cronológico o temático sino en "fragmentos" que, mediante la metáfora

\footnotetext{
8 En los meses posteriores al asesinato sistemático de varios líderes sociales, este poster fue reemplazado por la fotografía de Rubilda Rubiano quien aparece exhibiendo una fotografía de carné de su esposo, Aquileo Mecheche, líder de la comunidad embera asesinado el 12 de abril de 2019 en Riosucio (Chocó). Ella aparece con su cuerpo pintado de Jagua para honrar la memoria de su esposo y con un letrero con la siguiente inscripción "en medio del llanto y la selva, la comunidad "sembró" a [Aquileo]. No me dijeron "lo vamos a enterrar", sino "lo vamos a sembrar", lo regresan al lugar donde está su ombligo, con una planta de borojó".
} 
de un espejo roto, retratan distintos momentos del conflicto en varias regiones del país. La primera sala se denomina Tierra callada, se enfoca en fotografías que muestran el desplazamiento forzado; la segunda sala se llama No hay tinieblas que la luz no venza, reúne varios testimonios gráficos acerca de la desaparición forzada; la tercera sala se titula $Y$ aun así me levantaré referida a varios hechos violentos contra civiles, y la cuarta sala Pongo mis manos en las tuyas, muestra las iniciativas por la paz, los procesos de desmovilización y los proyectos mediante los cuales algunos excombatientes buscan reconstruir su vínculo con la sociedad y varios sectores de víctimas trabajan en la reparación del tejido social que fue dañado con la guerra. (Jesús Abad Colorado inaugura..., 2018 y Rondón, 2018).

Al final de la primera sala los visitantes pueden hacer una pausa para ver la proyección de imágenes en gran formato, varias de ellas a color, con una descripción en la cual se narra la situación que ocurría mientras se tomó la fotografía o donde se explica la razón por la cual se presentan imágenes de cultivos o de extensas selvas. Las primeras, se incluyen en la exposición, porque testimonian la concentración de la propiedad de la tierra en grandes empresas que la destinan a proyectos agroindustriales con los cuales expulsaron a los campesinos de sus tierras, y las segundas, aparecen porque ponen en evidencia la irreparable devastación de las fuentes de agua y de los bosques, por efecto de los enfrentamientos armados y los bombardeos. En las demás salas se incluyen otros recursos visuales (dibujos, gráficos, videos) que ponen en primer plano la voz de las víctimas o de excombatientes.

Los visitantes también encuentran información en los muros externos a las salas, con mapas que muestran el estado actual de la propiedad y tendencia de la tierra, y con cuadros estadísticos y resúmenes temáticos realizados por el Centro Nacional de Memoria Histórica y la Unidad de Víctimas en los que presenta la dimensión de la guerra en cifras (desaparición forzada, asesinatos selectivos, masacres, y enfrentamientos).

Estas cuatro salas no narran una historia lineal, ni presentan una estructura temática o cronológica, pero los visitantes pueden identificar distintos periodos y actores del conflicto armado y descubrir en las fotografías y en los textos que acompañan las imágenes, las historias de los grupos sobre los cuales ha recaído con mayor rigor e impunidad la guerra (campesinos, comunidades de paz, indígenas, afrocolombianos, mujeres y niños) y la destrucción de la fauna y flora del 
territorio nacional por efecto de los bombardeos y de los continuos enfrentamientos armados.

De este modo los espectadores se asoman a un fragmento de lo ocurrido en el pasado reciente de Colombia, a través de las imágenes que Jesús Abad Colorado ha logrado documentar en sus más de quince años de actividad profesional, sin la pretensión de un trabajo exhaustivo de registro, sino en palabras de la comisaria de la exposición María Belén Sáez, como un "testimonio desde el afecto, con la visión de la humanidad de las víctimas para hacerlas visibles, bellas y dignas" (Universidad Nacional de Colombia, 2018).

Desde los primeros días de su exhibición, esta exposición registró un importante número de visitantes y varios medios locales, nacionales e internacionales hicieron reseñas de su amplia recepción. Inicialmente fueron las secciones de arte y cultura de los periódicos, revistas y portales de internet las que invitaron a visitar esta exposición, con descripciones que procedían de la visita, la síntesis que presenta la página del Claustro de San Agustín o de entrevistas a Jesús Abad Colorado y a la comisaria María Belén Sáez (Jesús Abad Colorado inaugura..., 2018; No te pierdas la exposición..., 2018; El Testigo. Memorias..., 2018; López, 2018; Restrepo, 2019).

Posteriormente esta exposición, "pensada de manera orgánica como una obra en proceso siempre plástico y cambiante" fue transformando el Claustro de San Agustín en un "amplificador de la voz y la tragedia de las víctimas, al estar ubicado frente al Palacio de Nariño y a pocos pasos del Capitolio Nacional" (Universidad Nacional de Colombia, 2018), como se puede ver en las reseñas periodísticas que aparecieron después de la inauguración y en varios trabajos académicos publicados a propósito de la exposición.

A partir del análisis de algunos estudios y documentos periodísticos que abordan el trabajo de Jesús Abad Colorado y de la experiencia que se puede adquirir al recorrer esta exposición con una finalidad pedagógica, se pueden identificar tres efectos que tuvo esta muestra fotográfica en la opinión pública y que pueden ayudar a estructurar propuestas de enseñanza del pasado reciente: se restableció la importancia patrimonial de las fotografías del testigo para documentar la persistencia del conflicto armado colombiano; se mostró que las víctimas no son cifras sino proyectos vitales truncados; y se posicionaron las iniciativas de 
resistencia de la población afectada por la guerra como los proyectos políticos de mayor relevancia en los últimos años.

\section{EL PASADO RECIENTE EN IMÁGENES: ENSEÑANZA DE UNA HISTORIA VITAL}

El 2 de octubre de 2016 se realizó el plebiscito que buscaba refrendar el Acuerdo de Paz firmado el 26 de noviembre entre el gobierno de Juan Manuel Santos y las FARC. La mayoría de los votantes $(50,21 \%)$ no avaló el acuerdo lo cual condujo a un proceso de revisión y ajuste ocurrido entre el 2 de octubre y el 30 de noviembre de 2016 y a un nuevo texto que aprobó el Congreso de la República y que se firmó por las partes en un acto público realizado el 24 de noviembre del mismo año. El Acuerdo final para la terminación del conflicto y la construcción de una paz estable y duradera se encuentra en su fase de implementación, con un escaso porcentaje de cumplimiento.

En los resultados regionales del plebiscito que buscó legitimar este acuerdo entre la población, los contrastes en la votación mostraron que solamente aquellos que habían tenido que convivir con la guerra consideraban que su derecho a la paz era inaplazable, como ocurrió en Bojayá donde el "Si" obtuvo el 95\% mientras que, en las grandes ciudades ganó la abstención que alcanzó el 53\% en Bogotá, o ganó el "No" por efecto de la campaña de desinformación liderada por los opositores al acuerdo o por la identidad ideológica construida entorno al uribismo, como ocurrió en Medellín, ciudad que registró unas de las participaciones más altas del país, donde ganó el "No" con el 62,97\%.

Lo ocurrido con el plebiscito, el escaso cumplimiento del acuerdo de paz ${ }^{9}$, el asesinato sistemático de líderes sociales y el retorno del conflicto armado en varias regiones del país, constata que la guerra persiste en Colombia a pesar de los distintos acuerdos de paz que se han logrado concretar desde los años ochenta y que la comprensión de su devastación y de la necesidad de detener la confrontación sigue siendo un tema pendiente para la sociedad colombiana, que esta la exposición fotográfica puede ayudar a convertir en prioridad. A continuación, se presenta

\footnotetext{
9 Para un balance del cumplimiento del acuerdo a dos años de su implementación se puede consultar el informe realizado por Juanita Goebertus Estrada, José Daniel López, Carlos Ardila, David Racero, John Jairo Cárdenas, Wilmer Leal, Catalina Ortiz, David Pulido, Angélica Lozano, John Jairo Hoyos, Harry González, Temístocles Ortega, Roy Barreras, Iván Cepeda, Luis Fernando Velasco, María José Pizarro, Katherine Miranda, León Fredy Muñoz, Neyla Ruiz, Mauricio Toro, Inti Asprilla, y Antonio Sanguino, quienes conforman el grupo de parlamentarios que han promovido y defendido el acuerdo de paz en el Congreso de la República (2019).
} 
Sandra P. Rodríguez, Enseñanzas de "El Testigo": pensar la...

brevemente la manera como el impacto del trabajo de Abad Colorado en la opinión pública puede tener un saldo pedagógico invaluable.

IMPORTANCIA PATRIMONIAL DE LAS FOTOGRAFÍAS ACERCA DEL CONFLICTO ARMADO COLOMBIANO

El Claustro de San Agustín es un monumento nacional que desde el año 2006 hace parte de la Dirección de Patrimonio Cultural de la Universidad Nacional de Colombia. Esta entidad considera que el patrimonio es "una memoria activa de proceso, de futuro, que actualiza el pasado en cada acción de rememoración buscando dar espacio a voces ocultadas, acalladas o subalternas; creando nuevas maneras de hablar, pensar y construir la realidad social y la ciencia" (Universidad Nacional de Colombia, 2018).

Esta concepción del patrimonio permite que se presenten muestras como la de El Testigo, que inicialmente se propuso como exhibición temporal entre el 20 de octubre y el 17 de diciembre de 2018, luego se amplió al 31 de enero de 2019, posteriormente hasta abril de 2019, nuevamente se prolongó hasta el 20 de octubre de 2019 y más recientemente hasta febrero de 2020. No es posible saber si esta muestra fotográfica se convertirá en una exposición permanente, pero en diciembre de 2019, ya se contabilizaban más de 400 mil espectadores (Extienden cierre de exposición..., 2019).

La contribución de Jesús Abad Colorado es patrimonial porque logra que la memoria individual de quienes son protagonistas de sus fotografías transite hacia una memoria colectiva que cuestione los pilares de la identidad basados en las narrativas épicas de la guerra, para subvertirlos a partir de la empatía y el compromiso con el legado de quienes no pudieron ser. Esta operación patrimonial implica "sentir vitalmente la indignación ante la injusticia pasada" y comprometer a las futuras generaciones con la justicia que reclama "el recuerdo de los abuelos ofendidos" porque como afirma Reyes Mate "es más humana la indignación ante la injusticia pasada que la promesa revolucionaria" (2006, p. 208).

\section{LAS VÍCTIMAS NO SON CIFRAS SINO PROYECTOS VITALES TRUNCADOS}

Según Susan Sontag (2019), "el pie de una fotografía ha sido por tradición neutro e informativo: una fecha, un lugar, nombres". No ocurre lo mismo con las fotografías de la exposición de El Testigo porque cada foto no solamente cuenta una 
historia, sino que está acompañada de un texto que muestra la interacción del fotógrafo con esa realidad a la que busca aproximar a sus espectadores. El interés de Jesús Abad por generar reflexiones en quienes aprecian su trabajo, se muestra en el pie de foto de cada pieza. De este modo las víctimas de la guerra en Colombia dejan de ser cifras y pasan a tener identidad e historia, pasan a reclamar un lugar en la memoria nacional del conflicto armado y a controvertir versiones oficiales que niegan la existencia del conflicto y que minimizan sus efectos. Al respecto el mismo Jesús Abad Colorado plantea lo siguiente sobre sus fotografías:

Hay niños que llevan gallinas, otros van con sus perros, con sus cerdos, hay uno que lleva un mico, hay otro que lleva un pato pequeñito. $Y$ es eso también lo que hace distinta la exposición y a esa mirada: es entender que en una sociedad como la nuestra se debate mucho sobre estadísticas, cifras de desaparecidos, de asesinados, de secuestrados, de hectáreas robadas, de víctimas de la violencia. $Y$ yo lo que trato de hacer es ponerle un nombre, es una responsabilidad mía (...) Porque un campesino no es una cifra, no es su cuerpo. Más allá es su alma, todo lo que rodea la vida de un campesino. (Enciso, 2019).

Abordar la situación de las víctimas desde este enfoque contribuye a controvertir la orientación que se le está danto actualmente al Centro Nacional de Memoria Histórica por efecto de la posición sostenida desde años atrás por su actual director Darío Acevedo, quien además de negar la existencia del conflicto armado en Colombia, ha promovido acciones diferenciales y discriminatorias con algunos sectores de víctimas, en particular las del paramilitarismo y de los organismos estatales, como se pudo constatar en las denuncias realizadas en el mes de noviembre de 2019 cuando Acevedo propuso "modificar textos del piloto del Museo de la Memoria, eliminando palabras" (guerra, despojo) o "borrar capítulos enteros como el de la Unión Patriótica", lo que implicó que fuera citado a un debate de control político en la Comisión Segunda del Senado de la República (Las razones por las que..., 2019).

\section{INICIATIVAS DE RESISTENCIA DE LA POBLACIÓN AFECTADA POR LA GUERRA}

Una de las salas de la muestra fotográfica pone el acento en las distintas iniciativas sociales que la población ha construido en medio de la confrontación armada para mantenerse en sus territorios, restableciendo el tejido social con las 
comunidades sobrevivientes o viabilizando sus procesos organizativos a pesar de los efectos de la guerra. Algunos en medio de la tragedia de la guerra continúan con sus vidas como un acto de resistencia. Esto se aprecia en la fotografía del matrimonio de Beatriz García y Óscar Giraldo en el municipio de Granada (Antioquia) después de una incursión guerrillera ocurrida el 7 de diciembre de 2000 que dejó destruidos 200 inmuebles, 19 víctimas mortales y más de 20 heridos. En la fotografía se aprecia una novia en la entrada de la iglesia donde además se encuentra un letrero que dice "la guerra la perdemos todos, ayudemos todos a construir un proceso de paz". ${ }^{10}$

Otros como los integrantes de la Comunidad de Paz de San José de Apartado, ${ }^{11}$ son captados por el lente de Jesús Abad Colorado en medio del dolor que causó el asesinato de tres niños y cinco adultos en el año 2005 por un grupo de paramilitares, que en las versiones libres realizadas en el marco de la Ley 975 de 2005 han confesado sus crímenes y la complicidad del Estado. Esta comunidad ha construido un monumento con piedras que recuerdan los nombres de cada uno de quienes fueron asesinados, y Jesús Abad Colorado, regresa a la comunidad periódicamente como un acto de memoria y de solidaridad para que la Comunidad se mantenga activa. Estas son las prácticas de resistencia que se pueden apreciar en el trabajo periodístico de Colorado, y son las que finalmente trazan la ruta del aprendizaje político que la sociedad colombiana podría emprender.

\section{REFLeXIONES finALES}

Entre las fotografías más emblemáticas de esta exposición, se encuentran las de las comunidades del Atrato en el departamento del Chocó, en particular las de la Masacre de Bojayá, ocurrida el 2 de mayo de 2002 por efecto de la explosión de un

\footnotetext{
${ }^{10}$ Esta incursión fue realizada por 600 guerrilleros de las Farc que hicieron explotar un carro bomba en el comando de Policía. El Tribunal Administrativo de Antioquia condenó a la Nación porque el Estado Colombiano falló "en del deber de proteger a los ciudadanos y ordenó una millonaria indemnización a las víctimas" (Por toma de las FARC..., 2017).

${ }^{11}$ Ante las incursiones persistentes de fuerzas del Estado, los paramilitares y la guerrilla, un grupo de campesinos decidió en 1997 conformar una comunidad de paz en San José de Apartadó, una zona estratégica para el tráfico y un territorio con abundantes reservas de recursos que son objeto de disputa. Esta comunidad fue pionera en la conformación de otras zonas humanitarias y en la actualidad se encuentran más de cincuenta experiencias similares. Esta comunidad no permite la incursión de ningún actor armado, no proporcionan apoyo de ningún tipo para la confrontación, trabajan colectivamente la tierra para obtener soberanía alimentaria y tienen una práctica de memoria activa que mantiene vivo el recuerdo de los campesinos que han sido asesinados por mantener una posición de neutralidad activa en medio de la guerra (la comunidad ha sufrido desplazamientos y más de 200 de sus residentes ( $15 \%$ de su población) han sido asesinados en su mayoría por el Estado y el paramilitarismo (Courtheyn, 2019).
} 
"cilindro bomba" que, fue lanzado por miembros del bloque 58 de las FARC en medio de un enfrentamiento que sostenía con un grupo paramilitar de las AUC, para mantener el control del territorio del río Atrato, y que impactó en la iglesia donde se había refugiado la población civil.

Este hecho dejó como saldo entre 119 muertos y 98 heridos, la mayoría menores de edad. Abad Colorado en sus fotografías muestra las dimensiones de este hecho y los efectos para el futuro de una población que perdió muchos de sus niños en esta acción. Bojayá es uno de los municipios que masivamente se manifestó en favor de los acuerdos de paz y paradójicamente hoy se encuentra amenazada porque su territorio vuelve a ser disputado por el ELN y el grupo paramilitar de los Urabeños, quienes ingresaron el 31 de diciembre de 2019 al corregimiento de Pogue, del municipio de Bojayá y mantienen confinadas a 121 familiar en las riberas del rio Atrato. Esto sigue ocurriendo porque persiste la desigualdad y el abandono estatal y porque se requiere que los sectores urbanos para los cuales la guerra ha sido ajena, conviertan a Bojayá y a otros territorios del país, donde persisten los mismos problemas, en la prioridad de sus actuaciones políticas.

Las fotografías de Jesús Abad colorado son una incitación a comprometerse con una formación política que convierta la justicia social en una prioridad de las movilizaciones sociales en los próximos años. Reducir la desigualdad, contribuir con la justicia y la reparación, y trabajar colectivamente para que la guerra no se convierta como ya lo advertía Benjamin, ${ }^{12}$ en un permanente estado de excepción es una responsabilidad inaplazable para la educación.

\section{REFERENCIAS}

Bonilla Vélez, J. I. (2015). Algo más que malas noticias. Una revisión crítica a los estudios sobre medios-guerra. Signo y Pensamiento, 34(66), 62-78.

\footnotetext{
${ }^{12}$ En su octava tesis Benjamin muestra que el estado de excepción es la regla cuando prevalece la versión de los vencedores en consensos que critican el fascismo pero que no son capaces de ver qué lo produce. "Los oprimidos lo tenían más claro", lo expresa Reyes Mate (2006). "Por experiencia sabían que la triunfal marcha hacia delante de aquella sociedad tenía como contrapunto una existencia marginada de todas las conquistas, una vida en estado de excepción. Desde esa experiencia de marginación sistemática de los logros de la civilización, los oprimidos podían sorprenderse de la ceguera de quienes pretendían luchar contra el fascismo agrandando el alcance del estado de excepción, pero no se sorprendían de lo que estaba ocurriendo" (p. 146).
} 
Bonilla Vélez, J. I. (2018). El reflejo de Medusa. Fotografía, política de la imagen y barbarie en Colombia (Tesis de doctorado). Medellín: Universidad Nacional de Colombia.

Congreso de la República de Colombia. (2019) ¿En qué va el acuerdo de paz a un año del gobierno Duque? Retos y recomendaciones. Informe 01. Seguimiento multi-partidista a la implementación del acuerdo de paz. Bogotá: Congreso de la República de Colombia.

Courtheyn, C. (2019). Territorios de paz: otras territorialidades en la Comunidad de Paz de San José de Apartadó, Colombia. Territorios, 40, 291-318.

Decreto 1660 de 2019 (septiembre 12). Por el cual se reglamenta la composición y funcionamiento de la Comisión Asesora del Ministerio de Educación Nacional para la enseñanza de la Historia de Colombia, y se adiciona un artículo al Título 3, Parte 1, Libro 1 del Decreto 1075 de 2015. Bogotá: Diario Oficial.

Documental "El testigo" de Jesús Abad Colorado llega a los cines de Colombia. (2018, octubre 17). El Espectador. Recuperado de http://bit.do/fqx9z

El testigo. Memorias del conflicto armado colombiano en el lente y la voz de Jesús Abad Colorado. (2018, octubre 20). Arteinformado. Espacio iberoamericano del arte. Recuperado de http://bit.do/fqyaa

Enciso, A. M. (2019). Las fotografías son pulsaciones del alma. La obra de Jesús Abad Colorado. Al Día. Cultura. Recuperado de http://bit.do/fqFeM

Extienden cierre de exposición "El testigo" de Jesús Abad Colorado. (2019, mayo 10). El Tiempo. Recuperado de http://bit.do/fqycG

Giraldo, C. A., Colorado, J. A. y Pérez, D. (1997). Relatos e imágenes: el desplazamiento en Colombia. Santafé de Bogotá: Centro de Investigación y Educación Popular-CINEP.

Jesús Abad Colorado inaugura "El testigo', su exposición más ambiciosa. (2018, octubre 20). Revista Semana. Recuperado de http://bit.do/fqyaC

Jesús Abad Colorado, gana el Reconocimiento a la Excelencia del Premio Gabo 2019. (2019, septiembre 10). Entrevista. Fundación Gabo. Recuperado de http://bit.do/fqya9

Lara López, E. L. (2005). La fotografía como documento histórico-artístico y etnográfico: una epistemología. Revista Cuadernos de Literatura del Caribe e Hispanoamérica, 5,1-28. 
Las razones por las que el director del CNMH responderá ante el Congreso. (2019, noviembre 11). Revista Semana. Recuperado de http://bit.do/fqybj

Ley 975 de 2005 (julio 25) por la cual se dictan disposiciones para la reincorporación de miembros de grupos armados organizados al margen de la ley, que contribuyan de manera efectiva a la consecución de la paz nacional y se dictan otras disposiciones para acuerdos humanitarios. Bogotá: Diario Oficial.

Ley 1448 de 2011 (junio 10) por la cual se dictan medidas de atención, asistencia y reparación integral a las víctimas del conflicto armado interno y se dictan otras disposiciones. Bogotá: Diario Oficial.

Ley 1874 de 2017 (diciembre 27) por la cual se modifica parcialmente la ley general de educación, ley 115 de 1994, y se dictan otras disposiciones. Bogotá: Diario Oficial.

López, L. (2018, noviembre 6). "El testigo", memorias del conflicto en el lente de Jesús Abad Colorado. Publimetro. Recuperado de http://bit.do/fqykW

Mate, R. (2006). Medianoche en la historia: Comentarios a las tesis de. Walter Benjamin «Sobre el concepto de historia». Madrid: Trotta.

No te pierdas la exposición "El Testigo". (2018, octubre 20). Canal Capital. Recuperado de http://bit.do/fqybw

Oficina en Colombia del Alto Comisionado de las Naciones Unidas para los Derechos Humanos (2006). Desde la prisión, realidades de las cárceles en Colombia. Colombia: Proyecto de Fortalecimiento Institucional, Derechos Humanos y Situación Carcelaria de la Oficina en Colombia del Alto Comisionado de las Naciones Unidas para los Derechos Humanos con la financiación de la Unión Europea

Pérez Salazar, J.C. (2019, septiembre, 10). Las conmovedoras imágenes de Jesús Abad Colorado, el fotógrafo que mejor ha retratado el dolor de la guerra en Colombia. BBC Mundo. Recuperado de http://bit.do/fqyjU

Ponce de León, C. (2015). Jesús Abad Colorado. Mirar de la vida profunda. Bogotá: Planeta.

Por toma de las FARC a Granada, Antioquia, condenan a la Nación. (2017, octubre 9 ). El Colombiano. Recuperado de http://bit.do/fqybG

Restrepo, A.M. (2019, enero 14). Durante muchos años la fotografía ha sido la forma de contar este conflicto: Jesús Abad Colorado. Uniminuto Radio. Recuperado de http://bit.do/fqykB 
Rondón Chamorro, R. (2018, octubre 25). Jesús Abad Colorado, testigo mayor de la historia nacional de la barbarie. Las2Orillas. Recuperado de http://bit.do/fqykh

Simon, E. (2014). La Fotografía Colombiana Contemporánea. La Expresión de un Contexto. Revista Cuadernos de Literatura del Caribe e Hispanoamérica, 19, 65-84.

Sontag, S. (2019). Ante el dolor de los demás. México: Pengin Random Hose.

Universidad Nacional de Colombia. Dirección de Patrimonio Cultural. (2018, octubre). El testigo. Memorias del conflicto armado colombiano en el lente y la voz de Jesús Abad Colorado. Recuperado de http://bit.do/fqyjp

Yepes Muñoz, R. (2014). El escudo de Atenea: Cultura visual y guerra en Colombia. Cuadernos de música, artes visuales y artes escénicas, 9(2), 23-43. 
